\title{
A importância do contexto Amazônico no ensino de Botânica na Educação Básica
}

\author{
The importance of the Amazon context in the teaching of Botany in Basic Education \\ La importancia del contexto amazónico en la enseñanza de la Botánica en la Educación Básica
}

Recebido: 22/06/2021 | Revisado: 30/06/2021 | Aceito: 06/07/2021 | Publicado: 16/07/2021

\author{
Wygney da Silva Santos \\ ORCID: https://orcid.org/0000-0002-2745-5529 \\ Secretaria de Estado de Educação do Pará, Brasil \\ E-mail: wygney82@gmail.com \\ Robson Marinho Alves \\ ORCID: https://orcid.org/0000-0002-4075-3539 \\ Instituto Federal do Amapá, Brasil \\ E-mail: robson.alves@ifap.edu.br \\ Ana Cristina Andrade de Aguiar Dias \\ ORCID: https://orcid.org/0000-0001-8779-3557 \\ Universidade Federal do Pará, Brasil \\ E-mail: acaaguiar@yahoo.com.br
}

\begin{abstract}
Resumo
Objetivou-se neste trabalho verificar a opinião dos alunos do ensino médio (educação básica) sobre as estratégias utilizadas pelos docentes de Biologia da rede pública estadual de Tucuruí/PA para o ensino de Botânica no contexto amazônico. Os dados foram recolhidos a partir da aplicação de um questionário estruturado com questões objetivas, contendo perguntas referentes à importância do ensino de Botânica, às aulas práticas e os projetos realizados pelas escolas, às estratégias de ensino e recursos didáticos adotadas pelos professores, à Botânica e sua relação com a preservação ambiental. A análise dos dados coletados comprova a importância que os alunos dão ao ensino de Botânica ligado a preservação da Amazônia e o desinteresse pelo método tradicional de ensino e a necessidade de aulas práticas utilizando as áreas verdes da floresta amazônica. Os resultados apresentados neste estudo sugerem a implantação de um projeto educacional voltado ao ensino de Botânica nas escolas de educação básica, fundamentado em estratégias de ensino que enfatizem a realidade do aluno e a contextualização dos conteúdos respaldado em aulas práticas, utilizando os recursos da flora regional.
\end{abstract}

Palavras-chave: Ensino de biologia; Ensino médio; Botânica.

\begin{abstract}
The objective of this work was to verify the opinion of high school students (basic education) about the strategies used by Biology teachers from the state public network of Tucurui/PA for teaching Botany in the Amazon context. Data were collected from the application of a structured questionnaire with objective questions, containing questions regarding the importance of teaching Botany, practical classes and projects carried out by schools, teaching strategies and teaching resources adopted by teachers, Botany and its relationship with environmental preservation. The analysis of the collected data proves the importance that the students give to Botany teaching linked to the preservation of the Amazon and the lack of interest in the traditional teaching method and the need for practical classes using the green areas of the Amazon forest. The results presented in this study suggest the implementation of an educational project aimed at teaching Botany in basic education schools, based on teaching strategies that emphasize the student's reality and the contextualization of the contents supported by practical classes using the resources of the regional flora.
\end{abstract}

Keywords: Biology teaching; High school; Botany.

\section{Resumen}

El objetivo de este trabajo fue verificar la opinión de los estudiantes de secundaria (educación básica) sobre las estrategias utilizadas por los profesores de Biología de la red pública estatal de Tucuruí / PA para la enseñanza de la Botánica en el contexto amazónico. Los datos fueron recolectados a partir de la aplicación de un cuestionario estructurado con preguntas objetivas, conteniendo preguntas sobre la importancia de la enseñanza de Botánica, clases prácticas y proyectos realizados por las escuelas, estrategias de enseñanza y recursos didácticos adoptados por los docentes, Botánica y su relación con la preservación ambiental. El análisis de los datos recolectados evidencia la importancia que le dan los estudiantes a la educación en Botánica vinculada a la preservación de la Amazonía y el desinterés por el método de enseñanza tradicional y la necesidad de clases prácticas utilizando las áreas verdes de la selva amazónica. Los resultados presentados en este estudio sugieren la implementación de un proyecto educativo orientado a la enseñanza de la Botánica en las escuelas de educación básica, basado en estrategias didácticas que 
enfatizan la realidad del estudiante y la contextualización de los contenidos apoyados en clases prácticas utilizando los recursos de la flora regional.

Palabras clave: Enseñanza de la biología; Escuela secundaria; Botánica.

\section{Introdução}

O Ensino de Botânica no Brasil se caracteriza em grande parte no modelo tradicional de aprendizagem. De tal forma, a transmissão de conhecimento via professor aluno está engessada em recursos didáticos, como slides e livros que não contemplam imagens e o contexto da flora local. A contextualização do ensino baseada no uso de recursos didáticos que fazem parte da realidade do aluno, como: bosques, parques ecológicos, áreas verdes próximas das escolas, não são utilizados no processo de ensino-aprendizagem ligados à Botânica (Carraher, 1986; Coutinho et al., 2004; Dias, Schwarz \& Vieira, 2009).

Diante disso, o conteúdo se torna complexo devido à forma como é ministrado, além do mais, aulas totalmente descritivas, causam aversão e desinteresse aos alunos (Coutinho et al., 2004). Não à toa, o ensino de Botânica, em todos os níveis, tem sido motivo de preocupação. De fato, o quantitativo de pesquisas referentes a está temática, apesar de primários, tem crescido no Brasil. Ainda assim, o Ensino de Botânica em nosso país tem-se caracterizado como excessivamente teórico, desestimulante e subvalorizado no conjunto das ciências Biológicas (Kinoshita et al., 2006; Katon, Towata \& Saito, 2013; Ursi et al., 2018; Alves, Dias \& Gil, 2021).

Eventualmente são utilizadas apostilas com o conteúdo bem resumido, apenas com intuito de 'pincelar o assunto', deixando os alunos com uma visão passageira sobre importância que de fato os vegetais representam para os seres humanos. Além disso, percebe-se a não inclusão científica dos alunos ao mundo Botânico. Ademais, vários autores têm apontado a necessidade de melhorias no Ensino da Botânica (Arruda \& Laburú, 1996; Seneciato \& Cavassam, 2004; Towata, Ursi \& Santos, 2010; Silva, 2013; Alves, Dias \& Gil, 2021).

Recursos didáticos como vídeos sobre os ecossistemas, reportagens e documentários são utilizados, mas não fazem parte da rotina pedagógica no processo de ensino-aprendizado, desta forma o conteúdo se torna desvalorizado (Arruda \& Laburú, 1996). Segundo Carraher (1986), o conhecimento é tratado como um conjunto de informações que são difundidos pelos docentes aos alunos, que em sua maioria, não são transmitidos de maneira reflexiva, mas memorizados momentaneamente resultando em falta de interesse por parte dos alunos.

Raramente o ensino baseado na prática, almejando proporcionar ao estudante uma experiência de ensino, baseada nos sentidos, sensação, experimentação e práticas de campo é usado dentro do Ensino da Botânica, ao que se percebe os educadores sofrem uma certa amnésia da importância Vegetal. O uso de material botânico vivo ou mesmo a utilização/construção de exsicatas, que tragam a contextualização e levem em conta o dia a dia dentro da realidade do aluno, não fazem parte de uma dinâmica de ensino voltado para a Botânica, sobretudo no ensino fundamental e médio (Pereira \& Putzke, 1996).

Pesquisas, como trabalhos de conclusão de curso (TCC), dissertações, teses e artigos publicados, apontam para o mesmo problema, "o ensino de botânica não tem atraído mentes jovens" (Pieroni \& Zancu, 2017). Outra ideia muito presente em trabalhos publicados é que o ensino de Botânica não é valorizado dentro das Ciências Biológicas, de modo que o assunto sofre certo preconceito por uma parcela significativa dos professores (Kinoshita et al., 2006; Freitas et al., 2012; Salatino \& Buckerigde, 2016).

As dificuldades ao ensinar e aprender Botânica acontecem entre professores e estudantes. A aquisição do conhecimento em botânica é prejudicada não somente pela falta de estímulo em observar e interagir com as plantas, como também pela precariedade de equipamentos, métodos e tecnologias que auxiliam no aprendizado. Onde os docentes têm dificuldades em criar metodologias ativas de ensino, ficando o aluno distante da inclusão científica (Arruda \& Laburú, 1996; Ceccantini, 2006). 
Sobre o contexto supracitado, percebemos que as problemáticas enfrentadas ao ensinar Botânica são diversas. Nos quais os trabalhos acadêmicos e propostas publicadas para a melhoria do ensino de Botânica ainda são embrionários na Amazônia Oriental, sendo esse panorama, alvo de preocupação dos pesquisadores envolvidos nessa área de conhecimento (Silva \& Cavassan, 2006; Barbosa, Macedo \& Ursi, 2016; Pieroni \& Zancu, 2017; Ursi et al., 2017).

Cabe ressaltar a importância de estudos sobre o ensino de Botânica quando se trata da Amazônia, pois, este bioma corresponde a mais de $40 \%$ do território nacional e é constituído principalmente por uma floresta tropical. Nesse sentido, consideramos necessário conhecer as dificuldades relacionadas ao processo ensino-aprendizagem desse tema na educação básica (ensino médio) da região Amazônica, principalmente no município de Tucuruí/PA (sudeste do Pará). A relevância do estudo é factual para conhecer a verdadeira situação do ensino de Botânica nas escolas públicas da rede estadual de educação, para depois propor estratégias metodológicas exequíveis que visam melhorar o ensino desse tema na $16^{a}$ Unidade Regional de Ensino (URE) do Pará.

Nesse âmbito, objetivou-se nesse trabalho verificar a opinião dos alunos do ensino médio (educação básica) sobre as estratégias utilizadas pelos docentes de Biologia para o ensino de Botânica no contexto amazônico.

\section{Metodologia}

A pesquisa foi realizada em duas escolas públicas da rede estadual de ensino da $16^{\mathrm{a}}$ Unidade Regional de Ensino (URE), localizadas no município de Tucuruí, no estado do Pará, norte do Brasil, a saber: Escola de Ensino Médio Rui Barbosa e Escola Simão Jacinto do Reis. Por um período de 90 dias (3 meses), de março a junho de 2019, acompanhou-se quatro (4) turmas referentes ao terceiro ano do ensino médio, ou seja, concluintes da educação básica. Nesse período, analisamos a importância do ensino de Botânica, as aulas práticas e a aprendizagem, os projetos realizados pelas escolas, o conhecimento botânico aplicado na preservação ambiental, as estratégias de ensino adotadas pelos professores e os recursos didáticospedagógicos utilizados.

O estudo foi do tipo descritivo em que foram feitas análises e interpretações de dados de forma qualitativa e quantitativa. Para Pereira et al. (2018), os métodos qualitativos estão atrelados a interpretação dos pesquisadores sobre o tema, no qual frequentemente os procedimentos qualitativos se convertem em quantitativos pelo uso de questões objetivas. Para o questionário empregamos a escala Likert (1932), largamente utilizada para mensurar opiniões com um nível maior de gradação.

Participaram da pesquisa 138 alunos que estão concluindo a educação básica. Durante a vivência e o acompanhamento das aulas nas escolas mencionadas, os diretores e professores autorizaram a realização do estudo e aplicação dos questionários através da carta de anuência. Segundo a Resolução 466/12 do Ministério da Saúde, que dispõe sobre as diretrizes sobre as pesquisas envolvendo seres humanos, todos os indivíduos participantes da pesquisa assinaram um Termo de Consentimento Livre e Esclarecido (TCLE). Todos os documentos usados nesta pesquisa estão devidamente regulamentados pelo Comitê de Ética em Pesquisa da Universidade Federal do Pará (UFPA), sob o parecer 3.295.711.

Os dados foram coletados a partir da aplicação de um questionário estruturado contendo perguntas objetivas referentes aos seguintes tópicos: a importância do ensino de Botânica e das aulas práticas; o ensino de Botânica e a preservação ambiental. Os alunos responderam ao questionário individualmente e os resultados foram tabulados, analisados e expressos na forma de gráficos utilizando o "Microsoft Office Excel 2013". Por meio da análise das respostas foi possível verificar como os alunos da educação básica conseguem perceber as estratégias adotadas pelos professores e a importância do ensino de Botânica no contexto Amazônico. A interpretação dos resultados foi embasada em consonância com os fundamentos teóricos presentes no arcabouço desta pesquisa. 


\section{Resultados e Discussão}

\subsection{A importância do ensino de Botânica e das aulas práticas}

Participaram da pesquisa 138 alunos, na faixa etária entre 15 e 20 anos, sendo 82 (59\%) do sexo feminino e 56 (41\%) do sexo masculino. As informações coletadas afirmam que 70\% (96) dos alunos tiveram aulas de Botânica muito teóricas, descontextualizadas e com escassez de aulas práticas, focadas principalmente para o Exame Nacional do Ensino Médio (ENEM).

Os resultados evidenciaram que a maioria dos discentes (78\%) opinaram que o ensino de Botânica é importante e necessário para o ensino médio (Figura 1). Apesar do indicativo de importância, o conhecimento dos educandos sobre os conteúdos de Botânica ainda é limitado e pouco claro. As informações coletadas destacam que uma parte significativa dos alunos (22\%) não considera importante (razoavelmente, pouco ou não importante) o ensino de Botânica (Figura 1). Essa afirmativa, na visão deles, está relacionada às dificuldades de transmissão desses conhecimentos pelos docentes e a forma como os alunos enxergam as plantas, não reconhecendo as suas particularidades (cegueira botânica).

Portanto, torna-se relevante entender as dificuldades em relação ao processo ensino-aprendizagem que afetam a compreensão dos conteúdos. Além disso, é extremamente importante conhecer a flora local, por parte dos alunos, de exemplares amazônicos como recurso didático-pedagógico. Essa realidade pode garantir ao aluno a compreensão da grande riqueza florestal e da biodiversidade existente na Amazônia, além da sua importância ecológica e estratégica como fonte de recursos naturais, bem-estar da sociedade e laboratório vivo, onde se pode estudar as espécies e suas interações com o ambiente e com o homem (Dias, Schwarz \& Vieira, 2009).

É indispensável para a construção do conhecimento que o aluno estabeleça relações entre o novo e o que já é conhecido, possibilitando esclarecer e detalhar conceitos presentes no conteúdo de Botânica. Além disso, a didática adotada pelos professores pode abranger exemplares vegetais que estejam no entorno da escola, presentes no dia a dia dos alunos, já que a importância da Botânica é reconhecida por eles (Corrêa et al., 2016).

Figura 1. A importância do ensino de Botânica no ensino médio.

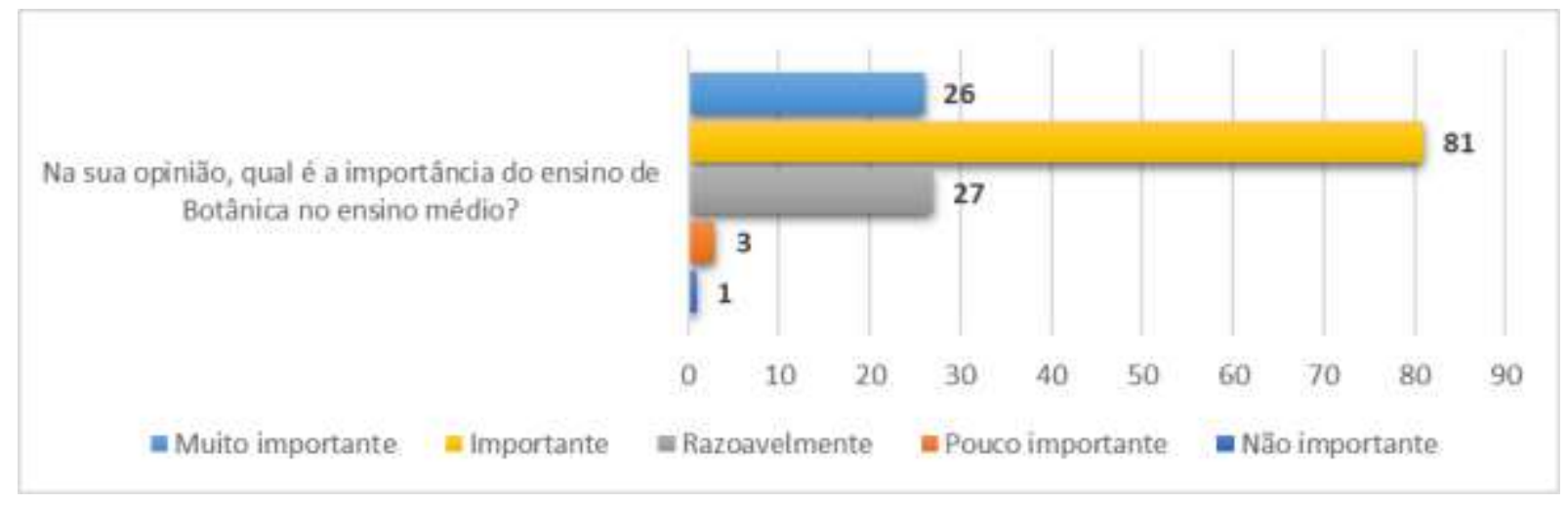

Fonte: Autores.

De acordo com os discentes (93\%), as aulas práticas podem melhorar consideravelmente o ensino de Botânica na educação básica (Figura 2). Os próprios dados revelam que os alunos não estão tendo aulas práticas/campo como estratégia de ensino na aplicação dos conteúdos botânicos, em que a teoria não deveria estar desvinculada da prática, pois esta metodologia é imprescindível para a construção do conhecimento científico dos alunos (Silva et al., 2015; Silva et al., 2021). Assim sendo, as estratégias de ensino que levem os alunos a áreas verdes para coleta de material botânico ou a montagem de um painel fotográfico demonstrando as particularidades dos plantas, podem ser utilizadas como recursos pedagógicos para despertar nos 
alunos o gosto pela Botânica, fazendo com que esse tema deixe de ser visto como um componente enfadonho e a aprendizagem seja prazerosa, dinâmica e criativa.

As aulas práticas são de suma importância para o ensino-aprendizagem da Botânica, pois despertam nos alunos a curiosidade e o interesse pelo assunto. Além disso, deve-se levar em consideração a inclusão dessas práticas no planejamento de aulas do ano letivo, pois a carga de conhecimento científico da Botânica envolve conteúdos diversos. Dessa forma os conteúdos de citologia, anatomia, morfologia, sistemática e fisiologia vegetal seriam ensinados baseados em práticas como, visitas a bosques e parques ou áreas verdes próximas a escola, construção de exsicatas, análise de material botânico coletado, montagem de painel fotográfico, ou seja, o discente aprende o conteúdo vivenciando a sua flora regional, que dificilmente aprenderia somente com aulas expositivas. Para Freire (1970), o aluno experimentando o que aprende, pode se apropriar dos conhecimentos e sua capacidade crítica-reflexiva se amplia perante a realidade, podendo intervir e recriar conceitos de acordo com sua nova forma de pensar. Além disso, aulas práticas podem permitir ao estudante observar, vivenciar e discutir conjunto de experiências e fenômenos biológicos e físico-químicos relacionados com seu cotidiano (Piochon, 2002).

Figura 2. As aulas práticas e a aprendizagem botânica.

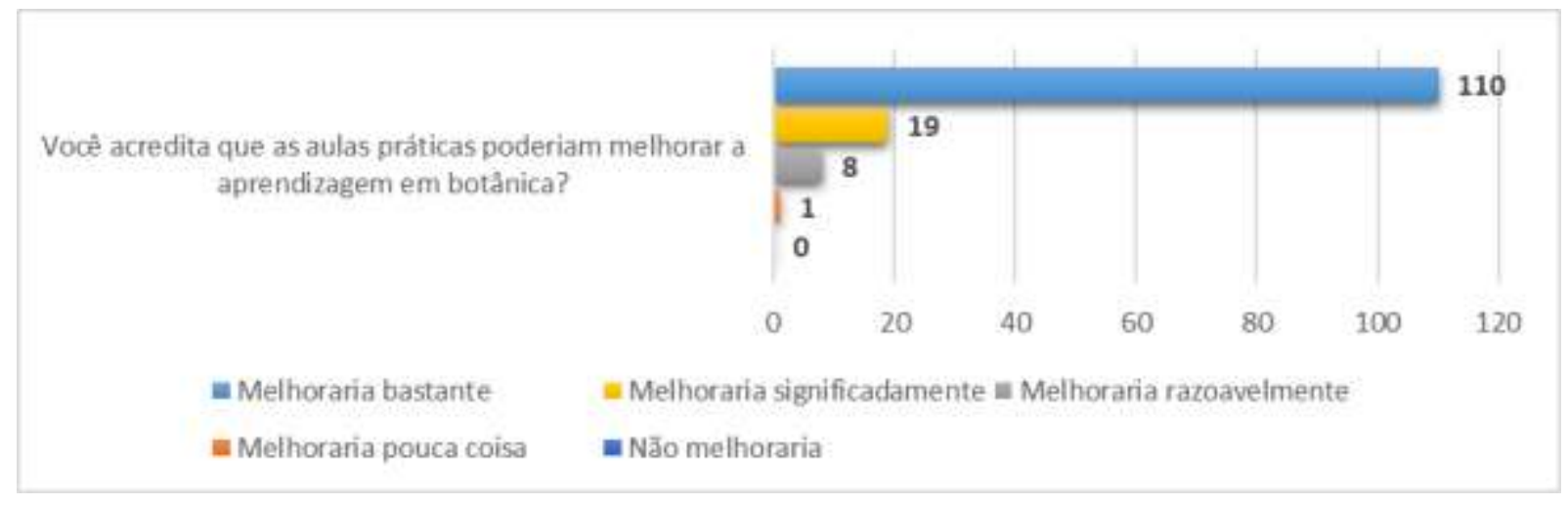

Fonte: Autores.

Os próprios alunos partícipes dessa pesquisa reforçam a necessidade de aulas práticas/campo como recurso didáticopedagógico para melhorar o ensino de Botânica no ensino médio. A maior parte dos discentes (95\%) enfatizam a importância das aulas em áreas verdes para a aprendizagem desse tema (Figura 3). No qual é notório a exiguidade dessas práticas ao ensinar esses conteúdos, e isso é preocupante, ainda mais tratando-se do contexto amazônico no qual a escolas pesquisadas estão inseridas e da importância que esse ecossistema tem na sociedade brasileira. Cabe ressaltar que utilização de plantas em aulas de laboratório apresenta várias vantagens, como disponibilidade ampla e fácil de material a ser coletado na natureza (Salatino \& Buckeridge, 2016).

Para Pereira e Putzke (1996), as aulas de campo mudam a visão que o aluno tem sobre o conteúdo, pois faz com que ele se sinta parte do processo de aprendizagem. $\mathrm{O}$ ato de examinar uma folha na lupa, ver os detalhes de uma flor e frutos, medir o tronco de uma árvore, avaliar se ela está doente ou saudável, identificar as relações existentes entre as espécies dentro de seu habitat, tudo isso, gera no aluno uma experiência de aprendizado de enorme valor para a construção do conhecimento científico (Silva et al., 2015). 
Figura 3. Aulas práticas de Botânica em áreas verdes e sua aprendizagem.

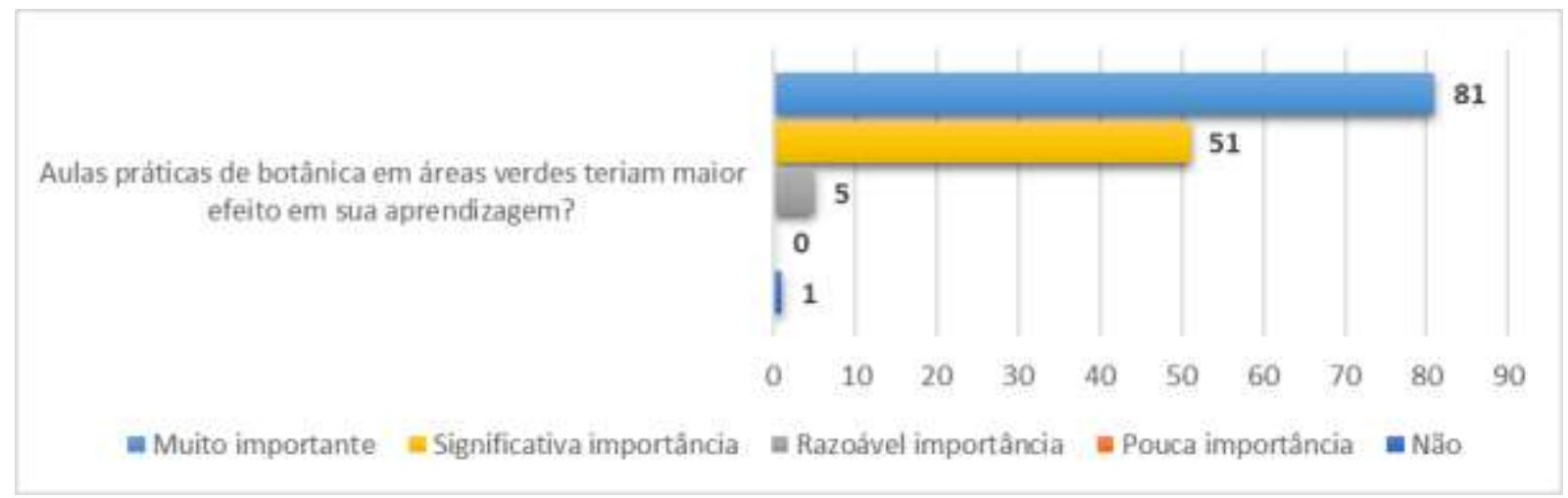

Fonte: Autores.

Convém destacar que as escolas pesquisadas apresentam projetos pedagógicos no âmbito cultural e socioambiental, além das mostras de ciências. Mas fica evidente, pelo relato dos professores e alunos, que não existe um projeto voltado para o ensino de Botânica. Diante disso, destacamos a necessidade da implantação de projetos voltados a esse tema na educação básica, que destaquem as experiências de aprendizado baseado em aulas práticas. Pois a ausência desses projetos repercute diretamente no nível de importância que os discentes manifestam em relação à Botânica.

Nesse sentido, a importância de um projeto envolvendo as aulas práticas como estratégias de ensino-aprendizagem é apoiada por diversos pesquisadores, assim como o uso de espaços verdes próximos as escolas. As aulas realizadas em ambientes naturais, aproveitando os espaços externos da escola, bem como as plantas disponíveis no local como complemento das aulas teóricas de Botânica, têm se mostrado uma metodologia eficiente no envolvimento e motivação dos alunos na construção do conhecimento (Santos \& Ceccantini, 2004; Ceccantini, 2006; Rodrigues, Miguel \& Lopes, 2013; Neris, 2013; Salatino \& Buckeridge, 2016).

\subsection{O ensino de Botânica e a preservação ambiental da Amazônia}

Nesse estudo observamos, através das respostas, a percepção dos alunos sobre a importância do ensino botânico e sua relevância para a preservação do meio ambiente. As opções 1, 2 e 5, maior quantitativo de respostas, refletem notoriamente a compreensão dos discentes sobre a preservação dos ecossistemas e dos recursos florestais e como eles são estratégicos para o desenvolvimento e do bem-estar da sociedade (Figura 4).

É perceptível o conhecimento dos alunos sobre a importância da preservação ambiental, mas é limitado em relação as espécies de plantas, no que tange a recuperação de áreas degradadas e nascentes (opção 3). Isto é, poucos alunos têm conhecimento botânico sobre as famílias botânicas e sua interação como o ambiente. E que, através desse conhecimento se escolhe as melhores espécies para utilização na recuperação de nascentes ou áreas degradas. Para Silva \& Andrade (2008), as metodologias de ensino devem sempre fazer associação entre o que é aprendido na sala de aula e o que o aluno vivencia em seu cotidiano. Por isso a importância de se contextualizar o ensino de Botânica usando recursos locais para o cotidiano do educando (Piochon, 2002).

O ensino de Botânica em seu plano de aula deve sempre contemplar os recursos locais, pois além de facilitadores, são excelentes recursos didáticos-pedagógicos de conscientização para a preservação e conservação ambiental. É fato que dificilmente se preserva o que não se conhece, partindo desse raciocínio fica evidente que quanto mais conhecimento os alunos tiverem sobre a Amazônia, mais capacidade crítica/reflexiva terão para agir como cidadãos nas decisões políticas que trazem impactos negativos para este ecossistema e seus recursos naturais. 
Figura 4. O conhecimento botânico e a preservação ambiental.

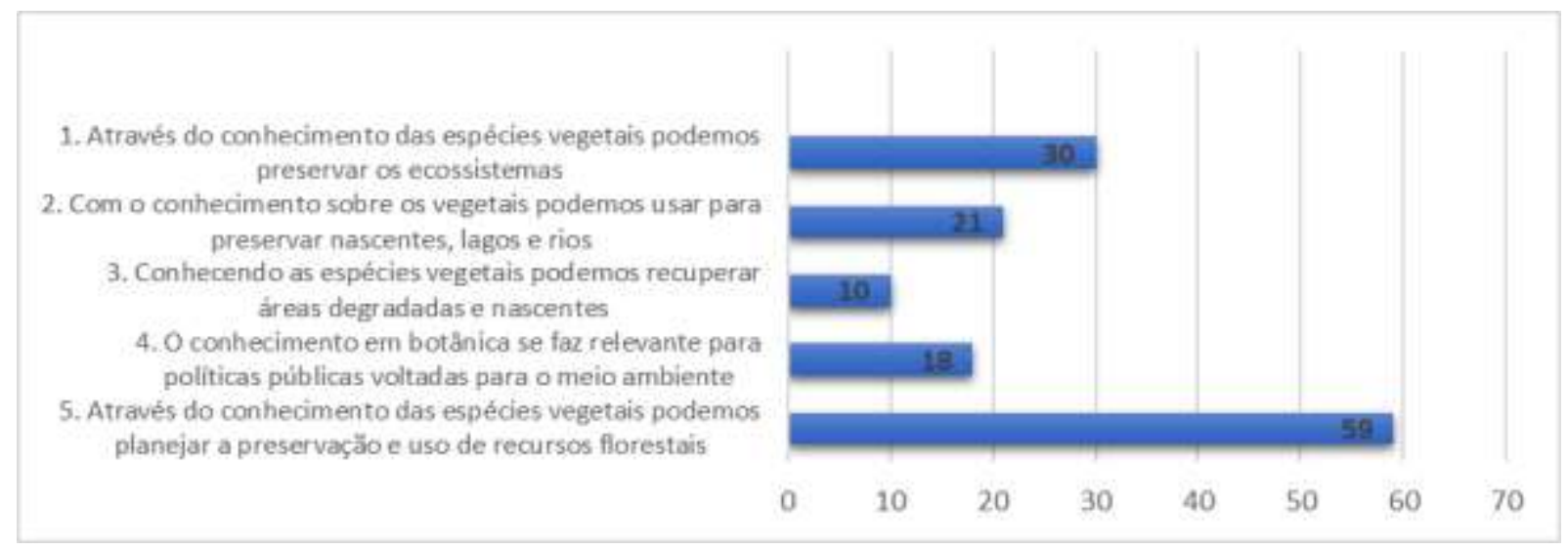

Fonte: Autores.

Os dados coletados também revelam que a maioria dos discentes (87\%) pesquisados consegue relacionar o conhecimento adquirido nas aulas de botânica ao seu cotidiano, ou seja, visualizam a importância das plantas no contexto amazônico, no qual é importante destacar o quanto o ensino de Botânica é significativo e importante na vida dos discentes ao fazerem uso deste. Vale ressaltar que o conhecimento dos educandos retratado nesse estudo sobre esse tema ainda é restrito e incipiente, mas mesmo sendo ínfimo tem efeito positivo na sua vida. Segundo Freire (1970), o conhecimento é compreendido e praticado no cotidiano do aluno, ou seja, quando ele se apossa da informação e reflete sobre a sua importância, modificando a sua visão mediante a sua realidade e utilizando o que aprendeu em sala de aula. Diante de tal contexto, vale ressaltar que o ensino de Botânica apresenta peculiaridades que justificam um olhar mais cuidadoso, meticuloso e específico durante o processo de ensino-aprendizagem. Por isso, é importante elaborar planos de aula que comtemplem em sua estrutura didáticopedagógica, elementos da flora local como instrumentos de ensino (Ursi et al., 2018).

Entretanto, uma parcela dos alunos (13\%) não declara nenhuma importância sobre o que aprendeu de Botânica na escola ao seu dia a dia, pois não conseguem relacionar esse conhecimento a função das plantas no ambiente. Esse fato gera uma preocupação, pois como os conteúdos estão sendo trabalhados nesse contexto? Percebe-se que o modelo tradicional de ensino baseado na memorização, não tem surtido efeito na aprendizagem entre os alunos do ensino médio. Além disso, os professores demonstram grande dificuldade em desenvolver atividades práticas que despertem a curiosidade dos educandos destacando a utilidade da Botânica no seu dia a dia (Santos \& Ceccantini, 2004).

Esta ausência de reconhecimento dos vegetais na alimentação, cosméticos, essências em perfumes, combustíveis, medicamentos, dentre outras, evidencia claramente a "cegueira botânica" (Ursi, Freitas \& Vasques, 2021). Para Wandersee \& Schussler (2001), o termo define a incapacidade de reconhecer a importância das plantas na biosfera e no nosso cotidiano, além das dificuldades em perceber os aspectos estéticos e biológicos exclusivos das plantas.

Pelas respostas dos alunos percebemos que eles têm um entendimento significativo sobre a importância da floresta amazônica e dos serviços ambientais que as árvores prestam para os seres humanos, no qual a maior parte deles afirma que as cidades podem melhorar a sua qualidade de vida, no ponto de vista ecológico, através de espaços verdes, praças, bosques ou parques (Figura 5). Mas somente 5\% (7) dos discentes tem conhecimento botânico de fisiologia vegetal marcando a opção 3 "Se faz necessária pelos serviços ambientais, como captura de carbono e fornecimento de sombra em cidades", que destaca o processo de fixação de carbono pelas plantas através da fotossíntese. Apesar de não demonstrarem um conhecimento significativo sobre esse conteúdo botânico, ainda assim as demais respostas refletem o conhecimento ecológico sobre a importância das plantas. Isso mostra a importância da contextualização dos conteúdos botânicos com o cotidiano do aluno e o 
uso de recursos locais de forma didática para promover uma aprendizagem significativa, pois segundo Feitosa e Leite (2012), uma das exigências atuais no ensino de biologia é a contextualização do assunto com o cotidiano do aluno.

Figura 5. A relação entre o ensino de Botânica e a qualidade de vida,

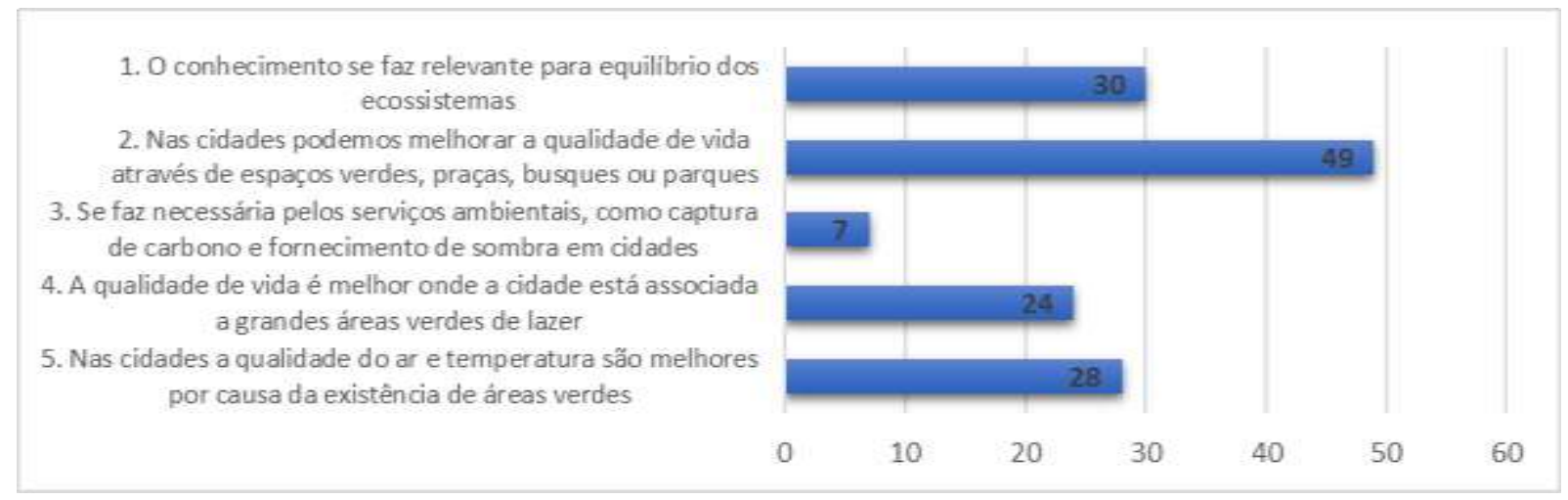

Fonte: Autores.

Em relação à aprendizagem dos conteúdos de botânica e sua aplicabilidade para a vida, observamos que grande parte dos alunos (91\%) reconhecem a importância do conhecimento desses assuntos para a valorização do ecossistema amazônico além do bem-estar socioambiental e econômico da região. Esses dados nos fazem refletir na importância das estratégias de ensino de Botânica no ensino médio de forma contextualizada, construtiva e significativa, para os educandos reconhecerem a importância que as plantas têm dentro do cenário amazônico e da sociedade brasileira. Tal realidade demonstra o quanto o ensino de Botânica é relevante para a sociedade, além da necessidade de se criar métodos de ensino-aprendizagem para atrair os jovens para a compreensão do mundo vegetal (Stanski et al., 2016; Towata, Ursi \& Santos, 2010; Ursi et al., 2018).

Contudo, uma parte dos discentes (9\%) retratou a importância desse conhecimento somente para a realização do ENEM (Exame Nacional do Ensino Médio) ou vestibulares nacionais, e poucos (1\%) manifestaram nenhuma importância em conhecer esse tema pois não pretendem trabalhar nessa área. Apesar das plantas estarem presente em nosso cotidiano, um pequeno número de discentes ainda não reconhece a sua importância no contexto ensino e Amazônia. Eles ainda não entenderam que somos dependentes dos vegetais e que sem as plantas a vida se torna inviável (Salatino \& Buckeridge, 2016).

No entendimento dos alunos pesquisados (86\%), o conhecimento dos conteúdos de Botânica é relevante como estratégia de conscientização e preservação dos recursos florestais no bioma amazônico. Eles apontaram claramente nas suas respostas a significância da floresta para a estabilidade dos ecossistemas e do bem-estar ambiental. Nota-se que o ensino de Botânica na educação básica é essencial na formação dos discentes nessa conjuntura, pois transformam os alunos em agentes capazes de esclarecer que esses recursos são estratégicos para a sociedade, não só financeiramente, mas como qualidade de vida (Towata, Ursi \& Santos, 2010; Salatino \& Buckeridge, 2016; Stanski et al., 2016; Ursi et al., 2018). Por isso, é importante a inclusão do aluno ao mundo científico, para que ele possa desenvolver aptidões e interesse na busca pelo conhecimento (Silva \& Andrade, 2008).

\subsection{O ensino de Botânica na Amazônia: Perspectivas e estratégias}

Como destacar o ensino de Botânica de forma que os alunos sintam satisfação em aprender? E por outro lado, os docentes demonstrem prazer em ensinar esse conteúdo? Buscar novas estratégias de ensino-aprendizagem perpassam por uma série de caminhos, dentre eles, o de trazer a Botânica para o cotidiano do aluno, em que os professores utilizem recursos da flora local como laboratório, no qual seus planos de aulas comtemplem visitas a áreas verdes, em que aconteça coleta de 
material botânico para a análise morfológica dos órgãos vegetativos (folhas, flores, frutos) e a construção de exsicatas, e tudo isso dentro do ambiente amazônico.

Nesse sentido, poderemos considerar as aulas mais dinâmicas e criativas com a utilização de materiais botânicos que estejam presentes nos arredores das escolas, em que o processo de ensinar botânica parta da primícia do que o aluno já conheça e vivencia no seu dia a dia a respeito da floresta amazônica, ao invés do livro didático ser a única fonte de conhecimento e informação sobre a flora local. Vale apenas ressaltar que a Amazônia é uma das últimas reservas de florestas contínuas do planeta e que quanto mais conhecimento sobre ela tivermos, mais se cria consciência de suas riquezas e importância tanto para os povos amazônicos como para quem a visita, pois está diante dos docentes e discentes um recurso didático extraordinário para despertar a curiosidade e o interesse científico pela botânica. Assim sendo, só precisamos desenvolver estratégias de ensino para tornar a ciência botânica mais ensinável para os alunos.

À vista disso (Figura 6), sugerimos estratégias para o ensino de Botânica que podem ser adotadas pelos docentes diante do contexto amazônico, facilitando a aprendizagem significativa dos discentes. Explicitamos, nesse panorama, pontos essenciais que o professor deve levar em consideração quando for montar a sua dinâmica de ensino ou plano de aula, para que os conteúdos de Botânica não sejam vistos de forma árida e entediante. Nesse ponto, destacamos o início desses aulas partindo da realidade do aluno e da contextualização dos conteúdos utilizando os recursos locais, por conseguinte tanto educador e educando passam a enxergar a Botânica com outros olhos, percebendo a importância das plantas em nossas vidas.

A ideia é fornecer caminhos e possibilidades, que podem ser considerados, no ensino de Botânica durante o processo ensino-aprendizagem, tendo como propósito maximizar a aprendizagem do aluno. Pois grande parte dos professores no ensino médio apresenta dificuldades em ministrar os conteúdos dessa área de conhecimento (Minhoto, 2003; Santos \& Ceccantini, 2004).

Em face do exposto, o primeiro passo está centrado na "Realidade do aluno", em que o educador pode buscar mecanismo pedagógicos, como uma breve auto apresentação, onde o aluno relata um pouco sobre sua vida e comunidade, além do motivo de ter ido estudar naquela instituição. Mediante isso, o docente com sua experiência encontrará pontos relevantes que podem ajudar no processo ensino-aprendizagem. Pois quando o discente associa o conteúdo aprendido com o mundo que o cerca, ele fica motivado com o aprendizado, não ficando um assunto isolado, mas com determinantes históricos e sociais que precisam ser considerados (Silva, Cavallet \& Alquini 2005).

O segundo passo será a "Contextualização do conteúdo" que será trabalhado. Essa contextualização deve levar em conta a realidade socioambiental dos discentes e os recursos da flora local disponíveis e de fácil acesso (Pereira \& Putzke, 1996; Willison, 2003). Diante disso, o professor terá uma ótima ferramenta didático pedagógica para consorciar a parte teórica trabalhada em sala com aulas práticas em áreas verdes. 
Figura 6. Estratégias que os docentes podem considerar no ensino de Botânica.

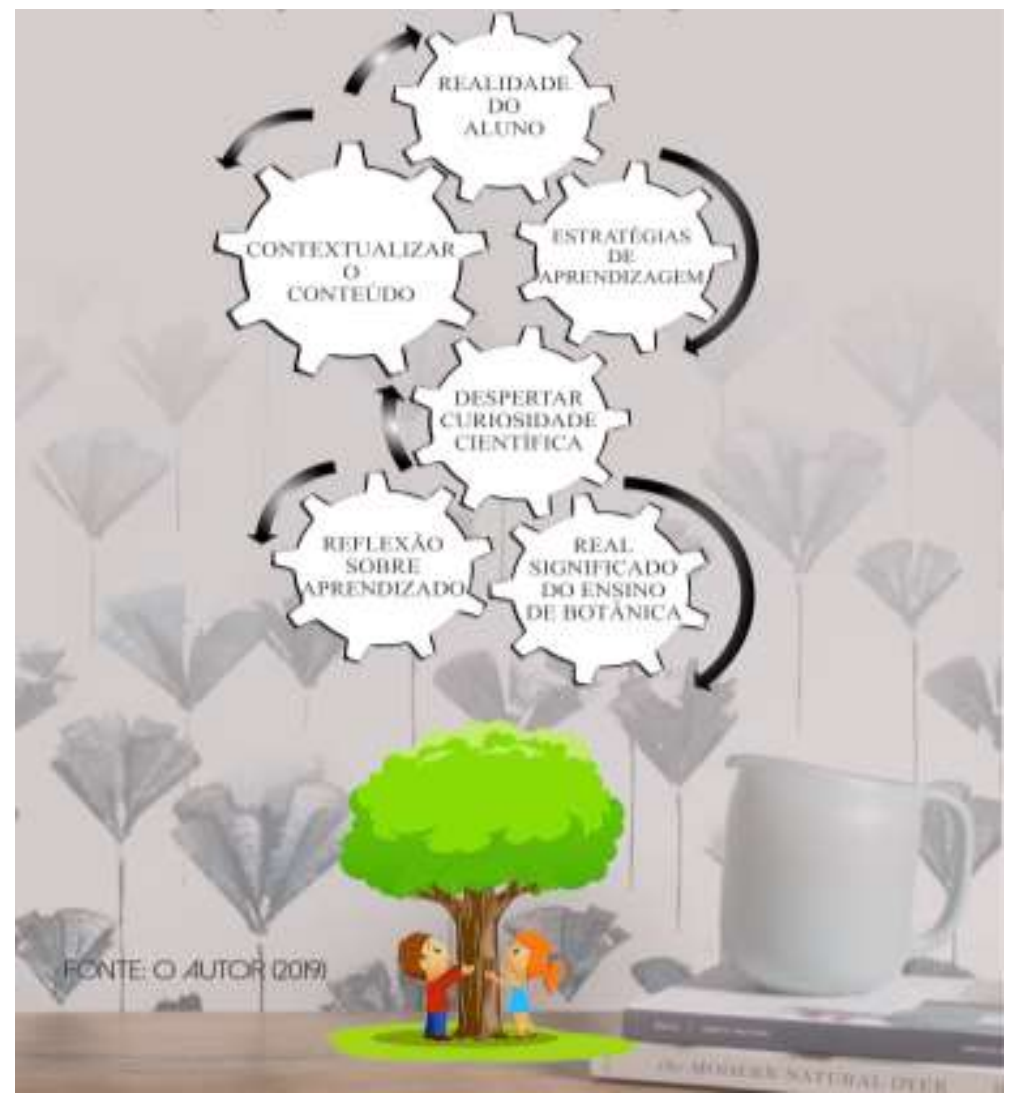

Fonte: Autores.

Dessa forma, a realidade dos discente podem contribuir para a elaboração/adaptação do plano de aula, o que nos leva ao terceiro passo “Estratégias de aprendizagem”. No qual as metodologias alternativas para ensinar os conteúdos de Botânica estão presentes em pesquisas voltadas ao processo de ensino-aprendizagem (Souza, Prata \& Maknamara, 2014; Matos et al., 2015; Uchôas \& Gomes, 2015; Ursi et al., 2018). Estratégias essas que diferem do modelo tradicional de ensino, tornando o ensino de Botânica prazeroso de ser aprendido pelo aluno (Coutinho et al., 2004). Uma estratégia muito presente em pesquisas e que pode muito bem ser usada no contexto das escolas da região amazônica é a visita a bosques, parques ecológicos ou áreas verdes próximas das instituições de ensino. À vista disso, um plano de aula que contemple uma visita a estes locais é amplamente viável como recurso didático pedagógico (Silva, 2008).

Estes três primeiros passos somados ao arcabouço teórico aqui referenciados, podem construir o quarto passo “Despertar da curiosidade cientifica”. Muito se fala da alfabetização cientifica, que segundo a Base Nacional Comum Curricular (BNCC), tem como objetivo principal proporcionar aos alunos o contato com processos, práticas e procedimentos de investigação científica para que eles sejam capazes de intervir na sociedade. Neste percurso, as vivências e interesses dos estudantes sobre o mundo natural e tecnológico devem ser valorizados (BNCC, 2018).

Ainda nesse sentido, a BNCC (2018), estabelece que o letramento científico deva ser desenvolvido ao longo do ensino fundamental e conseguinte aprimorado no ensino médio. A proposta é assegurar o acesso à diversidade de conhecimentos científicos produzidos ao longo da história por meio, por exemplo, da leitura, compreensão e interpretação de artigos e textos científicos e aos principais processos, práticas e procedimentos da investigação científica.

Acreditamos que o letramento científico dos alunos passa por um contínuo processo somatório, em que a contextualização do conteúdo, somada a interpretação da realidade dos discentes, leva o docente ao desenvolvimento de 
estratégias de ensino que acarretam o despertar da curiosidade científica, levando à inclusão científica chegando até o letramento científico proposto pela BNCC.

Como resultado desse processo, acreditamos que o ensino de Botânica alcançará dois caminhos: o "Real Significado do Ensino de Botânica" e a "Reflexão sobre o aprendizado". O real significado do ensino de Botânica está sujeito a ação dos docentes, tornando a apresentação desses conteúdos de forma mais dinâmica e prazerosa. E, por outro lado, os discentes passem a entender a importância da Botânica e como ela está presente em seu dia a dia. O outro resultado almejado é a reflexão sobre o aprendizado, ou seja, o intuito da educação é formar cidadãos que sejam capazes de opinar, criticar e avaliar políticas públicas ou decisões que afetam a sociedade. Uma boa educação, pautada na riqueza da floresta amazônica, terá maior efeito na conscientização dos alunos que dependerão desses recursos a médio e longo prazo. Nesse sentido, preconizamos a formação científica na Amazônia, sobre o ensino de Botânica, tendo como base o aprendizado científico e os princípios da "escola cidadã" legada por Freire et al. (1985).

\section{Conclusão}

O ensino de Botânica baseado em aulas práticas ainda é incipiente como estratégia de ensino na educação básica (ensino médio). Os dados constatam a importância que os alunos dão ao ensino de Botânica ligado à preservação do ambiente amazônico, visto que a escola pública recebe uma clientela de todas as camadas sociais e com isso sua diversidade sociocultural é extremamente ampla.

Os discentes reconhecem a importância da Botânica para a sociedade, apesar das dificuldades em assimilar esses conteúdos tendo como modelo o ensino essencialmente teórico e a carência de aulas práticas utilizando as áreas verdes do Bioma Amazônico.

As evidências são plausíveis que o ensino de Botânica no ensino médio segue o modelo tradicional, e que os alunos não demonstram interesse por esta dinâmica de aprendizagem. Sugerimos, através desse estudo, que o processo ensinoaprendizagem seja fundamentado em um projeto de ensino baseado nos seguintes tópicos: aulas primando a realidade do aluno e a contextualização do conteúdo; estratégias de aprendizagem baseadas em aulas práticas utilizando os recursos da flora regional; despertar a curiosidade através da alfabetização científica; o ensino de Botânica dinâmico e prazeroso; reflexão sobre o aprendizado com o objetivo de formar cidadãos críticos.

Reiteramos que esse projeto de ensino ou mesmo políticas educacionais sejam adaptados às realidades e aos contextos de cada escola, seus discentes e professores, visto que vivenciam cenários distintos, apesar de estarem no mesmo município. Pois quando se trata de desenvolvimento educacional, devemos observar sempre a realidade do aluno, o contexto históricosocial em que a escola está inserida, a dinâmica de como os professores trabalham o conteúdo e sua relação com os discentes e como a comunidade vê a importância da instituição como provedora de conhecimento científico.

Enfatizamos que esse trabalho é precursor no sudeste do estado do Pará, compreendendo a Amazônia Oriental, para tal conjuntura. Pesquisas meticulosas sobre o ensino de Botânica relacionado à preservação ambiental são primordiais na educação básica, principalmente no que tange a concepção de novas estratégias de ensino para facilitar aprendizagem dos alunos nas escolas do ensino médio.

\section{Referências}

Alves, R. M., Dias, A. C. A. A., \& Gil, A. S. B. (2021). Botânica no ensino superior: o que pensam os discentes do Amapá (Amazônia, Brasil). Research, Society and Development, 10(5), e55210515250. http://dx.doi.org/10.33448/rsd-v10i5.15250

Arruda, S. M. \& Laburú, C. E. (1996). Considerações sobre a função do experimento no ensino de Ciências. Pesquisa em Ensino de Ciências e Matemática, 5 , 14-24. 
Barbosa, P. P.; Macedo, M. \& Ursi, S. (2016). Uso das Tecnologias de Informação e Comunicação (TIC) no Ensino Contextualizado de "Fotossíntese": Uma Proposta para o Ensino Médio. Revista da SBEnBio, 9, 2244-2255.

Base Nacional Comum Curricular (2019). Ministério da Educação. Recuperado de: http://basenacionalcomum.mec.gov.br/historico

Carraher, T. N. (1986). Ensino de ciências e desenvolvimento cognitivo. Coletânea do II Encontro "Perspectivas do Ensino de Biologia". FEUSP.

Ceccantini, G. (2006). Os tecidos vegetais têm três dimensões. Revista Brasileira de Botânica, 29(2), 335-337.

Corrêa, B. J. S, Vieira, C. F., Orives, K. G. R., \& Felippi, M. (2016). Aprendendo Botânica no Ensino Médio por meio de Atividades Práticas. Revista da SBEnBio, 9, 4314-4324.

Coutinho, K. S., Detmann, E., Gomes, V. M., \& Cunha, M. (2004). A compreensão dos alunos do segundo ciclo fundamental a respeito do conteúdo básico da biologia vegetal. Anais do $54^{\circ}$ Congresso Nacional de Botânica. Belém (PA): CNBot.

Dias, J. M. C., Schwarz, E. A., \& Vieira, E. R. (2009). A Botânica além da sala de aula. www.diadiaeducação.pr.gov.br/portals/pde/arquivos/893-4.pdf

Feitosa, A. R., \& Leite, R. C. M. (2012). A formação de professores de Ciências baseada em uma associação de companheiros de ofício. Revista Ensaio, 14(1), $35-50$.

Freire, P. (1970). Pedagogia do oprimido: Paz e Terra.

Freire, P., Oliveira, R. D., Oliveira, M. D, \& Ceccon, C. (1985). Vivendo e aprendendo: experiências do IDAC em educação popular. (9a ed.), Brasiliense.

Freitas, D., Menten, M. L. M., Souza, M, \& Lima, M. I. S. (2012). Uma abordagem interdisciplinar da botânica no ensino médio. Moderna.

Katon, G. F., Towata, N., \& Saito, L. C. (2013). A cegueira botânica e o uso de estratégias para o ensino de botânica. Em A. M. Lopez [et al.]. (Org.), III Botânica no Inverno (pp. 179-183). São Paulo: Instituto de Biociências da Universidade de São Paulo.

Kinoshita, L. S., Torres, R. B., Tamashiro, J. Y., \& Forni-Martins, E. R. (2006). A botânica no ensino básico: relatos de uma experiência transformadora. São Carlos: RiMa.

Likert, R. (1932). A technique for the measurement of attitudes. Archives of Psychology, 140, 44-53.

Matos, G. M. A., Maknamara, M., Matos, E. C. A., \& Prata, A. P. (2015). Recursos didáticos para o ensino de botânica: uma avaliação das produções de estudantes em Universidade Sergipana. Holos, 5, 213-230.

Minhoto, M. J. (2003). Ausência de músculos ou porque os professores de biologia odeiam a Botânica. Cortez.

Neris, D. (2013). A importância das aulas práticas no ensino de botânica. Disponível em: http://biopedagogia.webnode.com.br/news/a-import\%C3\%A2nciade-aulas-praticas-no-ensino-de-bot\%C3\%A2nica/

Pereira, A. S., Shitsuka, D. M., Parreira, F. J., \& Shitsuka, R. (2018). Metodologia da pesquisa científica. UFSM.

Pereira, A. B., \& Putzke, J. (1996). Proposta Metodológica para o Ensino de Botânica e Ecologia. Editora Sagra.

Pieroni, L. G, Zancu, M. C. S. (2017). Ensino de Botânica: Um Estudo a Partir de Dissertações e Teses Defendidas no Brasil (1982 a 2016 ). Anais do IV CIECITEC.

Piochon, E. F. M. (2002). L'Expérimentation Assisté para Ordinateur et les Travaux Pratiques de Biologie em Prémière. (Mémoirepourl'obtention Du Diplôme d'Etudes Approfondies), Cachan, France: Ecole Normal e Supérieure de Cachan.

Rodrigues, M. R. S., Miguel, J. R., \& Lopes J. R. (2013). Abordagem do conteúdo de Botânica para o Ensino Fundamental utilizando áreas livres no espaço interno do colégio. Anais do Encontro de Pesquisa em Ensino de Ciências e Matemática: Questões atuais. UNIGRANRIO.

Salatino, A., \& Buckeridge, M. (2016). Mas de que te serve saber botânica? Estudos avançados, 30(87), 177-196. https://doi.org/10.1590/S010340142016.30870011

Santos, D. Y. A. C., \& Ceccantini, G. (2004). Propostas para o ensino de botânica manual do curso para atualização de professores dos ensinos fundamental e médio. São Paulo: Universidade de São Paulo.

Seneciato, T., \& Cavassan, O. (2004). Aulas de campo em ambientes naturais e aprendizagem em ciências - Um estudo com alunos do ensino fundamental. Ciência e Educação, 10, 133-147.

Silva, I. C. V., Andrade, I. M. (2008). Estratégias de ensino de Botânica no ensino médio em uma escola pública e uma escola privada de Sobral - CE. Essentia, 10(1), 21-35.

Silva, J. A., Santos, T. V. A., Lucena, E. M. P., Bonilla, O. H., Pantoja, L. D. M., Edson-Chaves, B., Mendes, R. M. S. (2021). Alunos do Ensino Médio da rede pública de Fortaleza-CE e o interesse pela Botânica. Research, Society and Development, 10(4), e18110413660. http://dx.doi.org/10.33448/rsdv10i4.13660

Silva, J. R. S. (2013). Concepções dos professores de Botânica sobre Ensino e Formação de Professores. (Tese Doutorado em Ciências na Área de Botânica) - Instituto de Biociências, Universidade de São Paulo, São Paulo. https://10.11606/T.41.2013.tde-22072013-085700

Silva, K. M., Araújo, M. L.; Maia, R. C., Farias, S. F., \& Nunes, T. G. R. (2015). Práticas lúdicas x Educação Ambiental: contribuindo para a conscientização na escola estadual Ruy Paranatinga Barata. Revista Brasileira de Educação Ambiental. 10(3), 221-234. https://doi.org/10.24109/21766681.rbep.86i213/214.839 
Research, Society and Development, v. 10, n. 8, e46910817459, 2021

(CC BY 4.0) | ISSN 2525-3409 | DOI: http://dx.doi.org/10.33448/rsd-v10i8.17459

Silva, L., Cavalet, V., \& Alquini, Y. (2005). Contribuição à reflexão sobre a concepção de natureza no ensino de Botânica. Revista Brasileira de Estudos Pedagógicos. 86(213/214), 110-120.

Silva, P. G. P. (2008). O ensino da botânica no nível fundamental: um enfoque nos procedimentos metodológicos. (Tese Doutorado em Educação para Ciências) - Universidade Estadual Paulista, Faculdade de Ciências. http://hdl.handle.net/11449/102000

Silva, P. G. P., \& Cavassan, O. (2006). Avaliação das aulas práticas de botânica em ecossistemas naturais considerando-se os desenhos dos alunos e os aspectos morfológicos e cognitivos envolvidos. Mimesis, 27(2), 33-46.

Souza, C. A. S., Prata, A. P. N., \& Maknamara, M. (2014). Utilização de frutos da vegetação do Sergipe como recurso didático para o ensino de ciências e biologia. Ciência em Tela, 7(2).

Stanski, C., Luz, C. F. P., Rodrigues, A. R. F., \& Nogueira, A. R. F. R. (2016). Ensino de Botânica no Ensino Fundamental: estudando o pólen por meio de multimodos. Hoehnea, 43(1), 19-25. https://doi.org/10.1590/2236-8906-34/2015

Towata, N., Ursi, S., \& Santos, D. Y. A. C. (2010). Análise da percepção de licenciandos sobre o Ensino de Botânica na educação básica. Revista da SBEnBio, 3(1), 1603-1612. Obtido de https://sbenbio.org.br/wp-content/uploads/edicoes/revista_sbenbio_n3/

Uchôas, E. G., \& Gomes, J. M. (2015). A construção da carpoteca como ferramenta de ensino e estratégia para a conservação da flora: um estudo de caso no INMG, Campus Arinos. Anais do Congresso de Ecologia do Brasil. SEB.

Ursi, S., Barbosa, P. P., Sano, P. T., \& Berchez, F. A. S. (2018). Ensino de Botânica: conhecimento e encantamento na educação científica. Estudos Avançados. 32(94), 7-24. https://doi.org/10.1590/s0103-40142018.3294.0002

Ursi, S., Barbosa, P., Saito, L. C., Towata, N., Cruz, P., \& Arouca, M. (2017). Conhecimento Pedagógico do Conteúdo "Algas" de estudantes de licenciatura em Biologia. Anais do XI Encontro Nacional de Pesquisa em Educação em Ciências. ENPEC.

Ursi, S., Freitas, K. C., \& Vasques, D. T. (2021). Cegueira Botânica e sua mitigação: um objetivo central para o processo de ensino-aprendizagem de Biologia. In: Vasques, D. T., Freitas, K. C., \& Ursi, S. (Ed.) Aprendizado ativo no ensino de botânica. São Paulo: Instituto de Biociências, Universidade de São Paulo, Cap. 2, p. 12-30.

Willison, J. (2003). Educação Ambiental em Jardins Botânicos: diretrizes para desenvolvimento de estratégias individuais. Rio de Janeiro: Rede Brasileira de Jardins Botânicos.

Wandersee, J. H., \& Schussler, E. E. (2001). Towards a theory of plant blindness. Plant Science Bulletin, 47(1), 2-9. https://botany.org/PlantScienceBulletin/psb-2001-47-1.php 